\title{
An Investigation of the Mediating Role of Procedural Justice in the Effect of Leader-Member Exchange (LMX) On Organizational Commitment
}

\author{
Mohammad Sadegh Hassanzadeh \\ Assistant Professor, Department of management, Payam Noor University, Tehran, Iran \\ Email: hassanzadeh.hr@pnu.ac.ir \\ Roozbeh Habibi \\ Assistant Professor, Department of management, Payam Noor University, Tehran, Iran \\ Email:drhabibir@gmail.com

\section{Fatemeh Norouzi Dogouri*} \\ MA, Public Administration, Payam Noor University, Tehran, Iran \\ ${ }^{*}$ Corresponding Author Email: fatemehnorouzi2011@ gmail.com
}

Doi:10.5901/mjss.2016.v7n3s3p259

\section{Abstract}

Organizational commitment is known as a critical factor in understanding and explaining behaviors related to employee's performance within organizations. Quality of Leader-member exchange leads to the perception of procedural justice and can turn into a useful tool for the staff to progress in their careers and make more commitment to organization. Therefore, the aim of this study was to examine the relationship among leader-member exchange, organizational commitment and procedural justice in the Social Security Organization of Rasht. A descriptive design for data collection as well as a correlational design was selected for this study and it followed a practical application. Some standardized questionnaires were used to collect the required data. These questionnaires were distributed among employees of Social Security Organization of Rasht who were selected using proportional stratified sampling. The data was then analyzed using PLS software. The reliability coefficient of the questionnaire for procedural justice and dimensions of LMX and organizational commitment was greater than 0.7. The results indicated a significant positive relationship between $L M X$ and procedural justice, LMX and organizational commitment as well as LMX and procedural justice and organizational commitment. Procedural justice was revealed to be a mediating variable between LMX and organizational commitment.

Keywords: Leader-Member Exchange, Organizational Commitment, Procedural Justice

\section{Introduction}

The Organization is a social system whose life and survival depends on existence of a strong relation between its constituent. In addition to tools and equipment, committed manpower is considered as the main and most essential factor in survival of the Organization. Given this, organizations are today faced with challenge of commitment of manpower (Ghasemi \& Keshavarzi, 2014, p.759). Organizational commitment enables management to capitalize on the diverse value of the workforce and to predict employee behaviors and attitudes through Leader-Member Exchange (LMX) and organizational justice (Leow \& Khong, 2009a, p.190). It seems logical that an organization with a committed force of workers may be better positioned than its competitors to meet the challenges posed by a dynamic marketplace. Thus, the pursuit of a more global understanding of the means by which organizational commitment develops is critical (McMahon, 2007, p.1).

When having a good exchange with the direct manager, employees can benefit mutual trust, support, effective communication, consideration, respect and credibility. Subsequently, as they enjoy job satisfaction, they will make more efforts and will bring prosperity for the organization (Rasouli \& Shahaie, 2009, p.73). Moreover, shortening the distance between the leader and the subordinate results in the leader's increased awareness of the needs, expectations and problems of a given employee in his or her job, which might undoubtedly contribute to the employee's more innovative and productive work performance (W.Turek \& D.Turek, 2013, p.44). 
Procedural justice may have strong impact on attitudes such as organizational commitment and trust in management (Ansari, Hung \& Aafaqi, 2007). Fair procedures indicate to the employees that the organization have high regards employees' self-respect, dignity and rights. Fair procedures actions imply that the organization has done something to distinguish itself from other organizations in the sense that reflects the level of concern that the organization has for its employees, thereby, providing a basis for employees to feel committed toward their organization (Nasurdin \& Ahmad, 2007, p.33). According to Tyler and Lind (1992), procedural fairness might be used as the basis by which employees establish longer relationships with their employers, enhancing their loyalty toward the organization (Ansari et al., 2007, p.694).

Social Security Organization is a public, non-governmental institution. This organization has broad interactions and face with a wide range of clients and stakeholders such as employees, policy holders, workers unions, administrative authorities and so on. As the staff's different attitudes and responses can negatively or positively affect customers' perception of the quality of services, creating a spirit of cooperation and organizational commitment among employees and improving the internal communications, including the communication between administrators and subordinates and vice versa can increase job satisfaction and process improvement. Thus, this results in client satisfaction and consequently increases resources, reduces costs and improves the quality of services. Injustice, unfair decisions and lack of positive two-way communication causes the lack of motivation, reduction of organizational commitment and lack of client satisfaction, as the main capital of the organization. Thus, this study can be a good reference to assist the authorities to achieve organization goals and accomplish defined missions.

\section{Literature Review}

\subsection{Leader - Member Exchange (LMX)}

Exchange includes mutual effective relationships that, over time, lead to growth and social development (Darvish \& Farzanehdokht, 2010). LMX indicates the relationship between the manager and each of his or her subordinates on the basis of reciprocal exchanges and interactions. This means that the behavior of each manager with his or her subordinates is different and this relationship can be of high or low quality depending on the subordinates' actions and efforts. This approach entails the concepts of some theories such as role theory, expectancy theory and social exchange theory. In the role theory, what manager expects the employees and the extent to which these expectations are met form the communication atmosphere of the exchange process. The expectation theory is based on the fact that a person is persuaded to show a particular behavior when, firstly, there is a possibility of reaping a reward and secondly, the reward is valuable and useful for him. Finally, based on the theory of social exchange, people seek to balance their social interaction with themselves and others (Rasouli \& Shahaie, 2009). Graen and Scandura (1987) proposed a vertical dyad linkage (VDL) development model where the leader and the member experience a role-taking, role-making, and roleroutinization process during early development of their relationship (Leow \& Khong, 2009a, p.166).

Initial dyadic exchange is the stage at which the leader initiates an assignment of tasks and begins to evaluate the behavior of the member and then makes a decision regarding responses to the member that this episode is called roletaking. Role-making is built on the mutual contribution of valued resources. Each party must offer something that the other party sees as valuable, and each party must see the exchange as reasonably fair (Lee, 2000). The third stage is role-routinization. At this point, leader and member develop a common understanding and clear mutual expectations. The behaviors of the leader and member become interlocked and the quality of exchange typically remains stable after this phase (Scandura \& Pellegrini, 2008, p.102).

\subsection{LMX Theory}

LMX theory states that, because of limited resources and lack of time to devote to each employee, the leader has an opportunity to develop a close social interaction or exchange with only a few essential subordinates (the in-group). This interpersonal social exchange matures and stabilizes into a dyadic relationship (Leow \& Khong, 2009a, p.164).

\subsection{Dimensions of $L M X$}

Liden and Maslyn (1998) gave a four factor model of LMX as follows (Yousaf, 2008):

Affect (the mutual affection members of the dyad have for each other based on interpersonal attraction); loyalty (the expression of public support); contribution (perception of the current level of work-oriented activity each member of 
the dyad puts forth); and professional respect (perception of the degree to which each member of the dyad has built a reputation of work-related activity) (Ansari et al., 2007, p.692). Affect and professional respect seemed to be representative of non-work factors, whereas contribution and loyalty clustered as work-related factors (Chooi et al., 2009, p.167).

\subsection{Organizational commitment}

Allen and Meyer (1990) define organizational commitment as "a psychological state that binds the individual to the organization (i.e., makes turnover less likely)" (Yousaf, 2008, p.1). Organizational commitment has been defined as a mindset that takes different forms and binds an individual to a course of action that is of relevance to a particular target (McMahon, 2007) and refers to the belief of personnel in the organizational values and goals and tendency to keep the membership of the organization and loyalty to the organization Also, the organizational commitment can be defined as a strong relation between the individuals' identities as their participation in organization (Ghasemi \& Keshavarzi, 2014). Researchers have found that a committed employee is one who stays with the organization through thick and thin, attends work regularly, puts in a full day's work and more, protects company assets, and shares the goal and vision of the organization. Katz and Kahn (1978) stated that organizations that value commitment among their employees assumed to reduce withdrawal behaviors such as lateness and turnover. In addition, Katz and Kahn (1978) said that committed employees may be more likely to engage in "extra-role" behaviors, such as creativeness or innovativeness, which often keep an organization competitive (Leow \& Khong, 2009a). Porter, Steer, Mowday and Boulian (1974) identified three related factors of organizational commitment: (1) a strong belief in an organization's goals and values, (2) a willingness to exert considerable effort for the organization, and (3) a strong desire to maintain membership in the organization (Lee, 2000, p.50).

The Three-Component Model of organizational commitment (Meyer \& Allen, 1991) has gained substantial popularity since its inception and commitment manifests itself in three relatively distinct manners (McMahon, 2007).

1. Affective commitment refers to identification with, involvement in, and emotional attachment to the organization (Yousaf, 2008, p.15; McMahon, 2007; Ahmed, 2014).

2. Normative commitment means that employees feel obligated to continue their employment with the organization. (Leow \& Khong, 2009b, p.150). This refers to the fact that people feel that they don't leave the organization because they are obliged and committed to the organization (Ghasemi \& Keshavarzi, 2014, p.761).

3. Continuance commitment relates to the costs associated with leaving the current job (Yousaf, 2008) This commitment occur when an employee remains with an organization largely out of need, whether due to lack of alternatives or costs associated with leaving, such as lost income, seniority or retirement benefits (McMahon, 2007).

\subsection{Procedural justice}

Organizational justice refers to people's perceptions about fairness in the workplace with regards to outcomes they receive in comparison to others, decision-making processes used to determine outcomes, and interactions with authority figures (Kiersch, 2014, p.15). According to Greenberg (1990), perceived organizational fairness can be classified in to three perspectives: distributive justice, procedural justice and interactional justice (Wang, 2014, p.40) . Unlike previous literature on organizational justice, Colquitt (2001) made use of four dimensions of organizational justice. He does not use interactional justice as a subset of procedural justice; rather he suggests that interactional justice be further broken down into interpersonal justice and informational justice dimensions (Yousaf, 2008, p.8) to cover two different angles of the interaction (Wang, 2014). Distributive Justice is "when employees perceive fairness of the outcomes that they receive in return for their inputs" (Ahmed, 2014). Interactional justice involves the manner in which organizational justice is communicated by supervisors to followers (Scandura, 1999, p.28). Interactional justice is the perceived by employee concerning how they are treated by their leader or decision-makers. Interpersonal justice discusses the Interpersonal treatment between employees and decision-makers, and informational justice relates to how employees are informed of the decision-makers and the adequacy of information provided to employee (Wang, 2014). Procedural justice refers to perceived fairness in the process of determining distributive outcomes, such as how pay or promotions are decided within an organization (Lambert, 2003; Chung, Jung, Kyle \& Petrick, 2010) and procedural justice focuses on the fairness of the manner in which the decision-making process is conducted (Lee, 2000). Procedural justice can be crafted if employees 
are involved in decision making in two ways. These two reasons: 1) It provides them a chance to be a part of and have their say in the decision making process (process control). 2) Employees can directly influence the decision making process and outcomes (decision control) (Ahmed, 2014, p.60).

Procedural justice embraces four different theories, consisting of self-interest model, the group value model, justice judgment theory and the fairness heuristic model (Pourezzat, Ehsani, Yazdani \& Fayez, 2013; Konovsky, 2000). The individual-level phenomenon is based on the "self-interest" or "instrumental" model that suggests, "Which is fair is that which benefits the individual" (Ansari et al., 2007, p.693). The group-value model has been proposed as a supplement to the self-interest model (Lee, 2000, p.33). This model stipulates that people value long-term relationships with groups because group membership is a means for obtaining social status and self-esteem (Konovsky, 2000, p.494). The justice judgment theory (Leventhal, 1980) states:

Procedural justice perceptions are based on six fairness criteria:

1. The Consistency Rule: the allocation procedures should be consistent across persons and over time.

2. The Bias-Suppression Rule: the personal self-interest and blind allegiance to narrow preconceptions should be prevented at all points in the allocative process.

3. The Accuracy Rule: the allocative process must be based on accurate information as much as opinion.

4. The Correct Ability Rule: the opportunities must exist to enable the allocative process to be modified (Lee, 2000).

5. The Representativeness Rule: the procedures reflect the concerns and needs of all persons affected (Kiersch, 2014).

6. The Ethicality Rule: the allocative procedures must be compatible with the fundamental moral and ethical values or standards accepted by that individual (Lee, 2000).

The fairness heuristic model addresses three important issues about justice. The first is that procedural justice is a substitute for honesty in the organization. Secondly, individuals' information about procedural justice affects their judgments about distributive justice. Thirdly, because of the ease of having access to information about it, evaluating the extent of procedural justice in the organization is easier than evaluating that of distributive justice (Pourezzat et al., 2013, p.72). The four-component model states four types of factors that people should have at the time of judging fairly: (a) evaluations of formal rules and policies related to how decisions are made in the group (formal decision making), (b) evaluations of formal rules and policies that influence how group members are treated (formal quality of treatment), (c) evaluations of how particular group authorities make decisions (informal decision making), and (d) evaluations of how particular group authorities treat group members (informal quality of treatment) (Blader \& Tyler, 2003). There are two main sources from which the evaluations about the extent of observance of procedural justice are derived: a) formal procedures and guidelines which are called formal bases of procedural justice; b) people's experiences with particular authoritative individuals in the group that are in charge of managing the groups. This aspect is called informal bases of procedural justice (Hezarjaribi, 2011, pp.46-47).

\subsection{The relationship between research variables}

\subsubsection{Leader-member exchange, organizational commitment and organizational justice}

The perception of the quality of interpersonal relationships leads to the recognition of the group level. This perception and knowledge then makes people either committed or non-committed and force them to endure or leave the organization. In short, it is anticipated that LMX will recognize the procedural justice atmosphere, which in turn leads to attitudinal outcomes, organizational commitment and turnover intention. In their study, Ansari et al. (2007) concluded that procedural justice atmosphere works as a mediator for the effect of LMX respect on three components of organizational commitment.

Yousaf (2008) found all aspects of organizational justice as a mediator in the relationship between LMX and organizational commitment. Lee (2000) predicted that distributive and procedural justice mediates in the relationship between LMX, job satisfaction, organizational commitment and turnover intention. LMX is positively correlated with variables of subordinates' attitudes such as overall satisfaction, satisfaction with supervisor and organizational commitment. LMX is also negatively correlated with turnover. In addition, LMX has a relationship with subordinates' perception of organizational justice.

Thus, the main hypothesis of the study is proposed as follows:

- Procedural justice plays a mediating role in the relationship between leader-member exchange (LMX) and organizational commitment. 


\subsubsection{The relationship between LMX and organizational justice}

According to LMX theory, leaders have limited resources such as discretion and time and they selectively distribute these resources among different group members. These exchange relationships between leaders and subordinates form employees' justice perceptions of organizational policies and practices just as distributive and procedural justice aspects. Scandura (1999) examined literature on LMX from organizational justice perspective and studied the relationship between the two constructs. He noted the attitudes and behaviors of employees falling into the categories of in group members (Having high quality relationship) and out group members (having low quality relationship). He had different findings compared to other researchers who found that in-group members receive more work related benefits in comparison to out-group members. Scandura suggests that differentiation of members in to in group and out group does not necessarily translate into organizational in justice. It rather depends on the perceptions of the members about the leader. If members perceive their leaders to use fair procedures for allocation of rewards etc, then they will perceive procedural justice and not injustice. Likewise, if members receive from their supervisor correct communication about reasons for distribution of rewards, then again interactional justice will be perceived by members despite members belonging to different groups. It is through proper way of communication (interactional justice) that even perceptions of employees of procedural and distributive injustice (in the cases where they make social comparisons) can also be changed (Yousaf, 2008, pp.17-18). Lee (2000) examined the relationship between LMX and procedural justice, and stated that LMX is the positive predictor of procedural and distributional justice. Wang et al. (2010) also demonstrated a significant relationship between LMX and procedural justice. Ansari et al. (2007) found professional respect of LMX as the only aspect that correlates with and positively and strongly affects procedural justice.

Thus, the first sub-hypothesis of the study is proposed as follows:

- There is a significant relationship between LMX and procedural justice.

\subsubsection{The relationship between LMX and organizational commitment}

In a study conducted by Ansari et al. (2007), it was demonstrated that the interest aspect of LMX is associated with all components of affective commitment. However, this effect was negative for constant commitment. On the other hand, the contribution aspect correlates with all the components of organizational commitment but emotional commitment. Hung et al. (2004) showed that professional respect had a positive impact on affective commitment and the contribution aspects changed into the predictor of normative commitment. In LMX, the interest aspect negatively impacted constant commitment, while the contribution aspect positively affected it. Reviewing previous studies, Leow and Khong (2009) stated that the findings of LMX studies have constantly shown that LMX has a positive relationship with organizational commitment. Therefore, LMX can be a useful tool for the staff to progress in their career life and to improve their commitment to the organization.

Thus, the second research hypothesis is proposed as follows:

- There is a significant relationship between LMX and organizational commitment.

\subsubsection{The relationship between organizational justice and organizational commitment}

Tyler and Lind (1992) found that procedural fairness may be used as the basis by which people establish larger relationships with their employers, enhancing their loyalty toward the organization. In this regard, several studies supported the relationship between perceptions of fairness and organizational commitment, and specified the contribution of procedural fairness to organizational commitment (Lee, 2000, p.60).

Ansari et al. (2007) declared that procedural justice atmosphere is associated with all the elements of commitment. However, the effect of constant commitment is less than affective and normative commitment.

Perceptions of procedural justice give employees feelings of "Perceived Organizational Support" (POS) which gives higher sense of organizational commitment and fewer intentions to quit. Organizations that provide equitable and fair rewards for their employees can increase the level of commitment shown by their employees (Yousaf, 2008). Similarly, Loi et al. (2006) found that affective commitment has a strong affirmative linkage with procedural justice other than continuance and normative commitment. If fair procedures are carried out in the organization, it would lead to a strong emotional attachment among employees (Ahmed, 2014, p.60). Yousaf (2008), Bakhshi et al. (2009), Ansari et al. (2007), Leow and Khong (2009) as well as Bahramzadeh and Yadegari (2009) found a significant and positive relationship between procedural justice and organizational commitment. Ahmed (2014) and Wang et al. (2010) showed a strong positive relationship between procedural justice and emotional commitment. In addition, Dehqanian et al. (2012) 
demonstrated that procedural justice has a positive and significant relationship with emotional and normative commitment, but no significant relationship with constant commitment.

Thus, the third sub-hypothesis in this study is as follows:

There is a significant relationship between procedural justice and organizational commitment.

Given the above assumptions, the conceptual model of the study is presented as below:

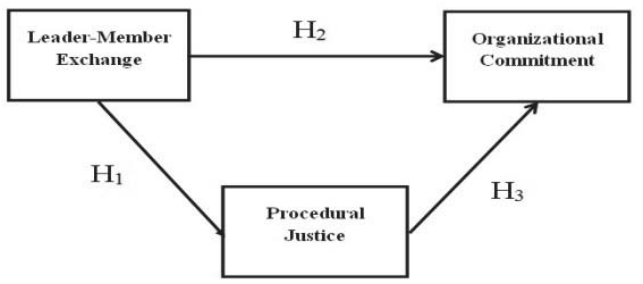

Figure 1: Conceptual model of the study

\section{Methodology}

The present study examined the relationship between LMX variables as the independent variable, organizational commitment as the dependent variable and procedural justice as a mediator. Therefore, it follows a practical application and as it describes the status of variables and the effect of the relationship among them, it selects a descriptive design regarding the data collection. It is also a correlational study as it uses correlation analysis, regression analysis and structural equation of simultaneous relationships between variables.

\subsection{Data collection tools}

The library study and field research as well as some questionnaires were used to collect the required data. According to Table (1), three types of questionnaires were used in this study. Liden and Maslyn's (1998) standardized questionnaire was used to measure LMX, Allen \& Meyer's (1990) standard questionnaire was adopted to measure organizational commitment and Lee's (2000) questionnaire was used to measure procedural justice. A five-point Likert scale was also used to answer the questionnaire items. Ansari et al. (2007) also used the above-mentioned questionnaires to measure LMX variables and organizational commitment. In his study, Lee (2000) adopted the standard questionnaire of Niehoff and Moorman (1993).

Table 1: Variables, aspects and number of items in the questionnaire

\begin{tabular}{|c|c|c|c|c|c|}
\hline Variables & Aspects & Number of items & Items & Reverse items & Source \\
\hline \multirow{4}{*}{ LMX } & Affect & 3 & $1,2 \& 3$ & \multirow{4}{*}{ - } & \multirow{4}{*}{ Liden \& Maslyn (1998) } \\
\hline & \begin{tabular}{|l} 
Loyalty \\
\end{tabular} & 3 & $4,5 \& 6$ & & \\
\hline & Contribution & 3 & $7,8 \& 9$ & & \\
\hline & professional respect & 3 & $10,11 \& 12$ & & \\
\hline \multirow{3}{*}{ Organizational commitment } & affective commitment & 8 & $1-8$ & $4,5,6 \& 8$ & \multirow{3}{*}{ Allen \& Meyer (1990) } \\
\hline & Continuance commitment & 8 & $9-16$ & $9,12 \& 18$ & \\
\hline & normative commitment & 8 & $17-24$ & $19 \& 24$ & \\
\hline Procedural justice & - & 15 & $1-15$ & - & Lee (2000) \\
\hline
\end{tabular}

\subsection{Validity and reliability of the measurement tools}

Although this study used a questionnaire to assess the desired structures, the content validity of the questionnaire was evaluated by management experts. In addition, to ensure the comprehensibility of items, their face validity was confirmed by ordinary individuals and non-experts. The reliability of indicators was also measured using internal consistency reliability (Cronbach's alpha), composite reliability and factor weights or factor loadings. Factor loading indicates the extent to which items represent their corresponding structures. In the present study, all the items enjoyed factor loadings greater than 0.7 on the corresponding variable; this is demonstrated in Table (2). 
Table 2: Factor loading test $(\mathrm{LMX}=$ Leader-member exchange, $\mathrm{OC}=$ Organizational commitment $\& \mathrm{PJ}=$ Procedural justice)

\begin{tabular}{|c|c|c|c|c|c|c|c|c|}
\hline Items & $\begin{array}{c}\text { Affective } \\
\text { commitment }\end{array}$ & $\begin{array}{l}\text { Continuance } \\
\text { commitment }\end{array}$ & $\begin{array}{c}\text { Normative } \\
\text { commitment }\end{array}$ & $\begin{array}{l}\text { Procedural } \\
\text { justice }\end{array}$ & Affect & Loyalty & Contribution & $\begin{array}{c}\text { Professional } \\
\text { respect }\end{array}$ \\
\hline LMX1 & & & & & 0.938 & & & \\
\hline LMX2 & & & & & \begin{tabular}{|l|}
0.894 \\
\end{tabular} & & & \\
\hline LMX3 & & & & & 0.965 & & & \\
\hline LMX4 & & & & & & 0.949 & & \\
\hline LMX5 & & & & & & 0.763 & & \\
\hline LMX6 & & & & & & 0.909 & & \\
\hline LMX7 & & & & & & & 0.914 & \\
\hline LMX8 & & & & & & & 0.858 & \\
\hline LMX9 & & & & & & & 0.903 & \\
\hline LMX10 & & & & & & & & 0.916 \\
\hline LMX11 & & & & & & & & 0.927 \\
\hline LMX12 & & & & & & & & 0.765 \\
\hline OC1 & 0.890 & & & & & & & \\
\hline OC2 & 0.792 & & & & & & & \\
\hline OC3 & 0.764 & & & & & & & \\
\hline OC4 & 0.823 & & & & & & & \\
\hline OC5 & 0.864 & & & & & & & \\
\hline OC6 & 0.876 & & & & & & & \\
\hline OC7 & 0.837 & & & & & & & \\
\hline OC8 & 0.849 & & & & & & & \\
\hline OC9 & & 0.857 & & & & & & \\
\hline OC10 & & 0.902 & & & & & & \\
\hline OC11 & & 0.898 & & & & & & \\
\hline OC12 & & 0.879 & & & & & & \\
\hline OC13 & & 0.837 & & & & & & \\
\hline OC14 & & 0.828 & & & & & & \\
\hline OC15 & & 0.760 & & & & & & \\
\hline OC16 & & 0.866 & & & & & & \\
\hline OC17 & & & 0.825 & & & & & \\
\hline OC18 & & & 0.877 & & & & & \\
\hline OC19 & & & 0.828 & & & & & \\
\hline OC20 & & & 0.917 & & & & & \\
\hline OC21 & & & 0.808 & & & & & \\
\hline OC22 & & & 0.860 & & & & & \\
\hline $\mathrm{OC} 23$ & & & 0.848 & & & & & \\
\hline OC24 & & & 0.869 & & & & & \\
\hline PJ1 & & & & 0.882 & & & & \\
\hline PJ2 & & & & 0.752 & & & & \\
\hline PJ3 & & & & 0.772 & & & & \\
\hline PJ4 & & & & 0.824 & & & & \\
\hline PJ5 & & & & 0.917 & & & & \\
\hline PJ6 & & & & 0.833 & & & & \\
\hline PJ7 & & & & 0.913 & & & & \\
\hline PJ8 & & & & 0.728 & & & & \\
\hline PJ9 & & & & 0.869 & & & & \\
\hline PJ10 & & & & 0.804 & & & & \\
\hline PJ11 & & & & 0.862 & & & & \\
\hline PJ12 & & & & 0.842 & & & & \\
\hline PJ13 & & & & 0.860 & & & & \\
\hline PJ14 & & & & 0.785 & & & & \\
\hline PJ15 & & & & 0.823 & & & & \\
\hline
\end{tabular}


In order to analyze the validity of measurement tools, convergence validity (calculation of the average variance extracted (AVE)) and divergent validity (square root of AVE) were used. In PLS analysis, according to Fornell and Larcker (1981), the minimum amount of AVE must be equal to 0.5 , which indicates sufficient value for convergent validity, meaning that a latent variable can, on average, explain more than half of the dispersion of its representatives. The results of examining the values of alpha (a), composite reliability (CR), average variance extracted (AVE) and square root are shown in Table (3).

Table 3: Reliability and validity indices

\begin{tabular}{|l|c|c|c|c|c|c|c|c|}
\hline $\begin{array}{l}\text { Research } \\
\text { constructs }\end{array}$ & $\begin{array}{c}\text { Affective } \\
\text { commitment }\end{array}$ & $\begin{array}{c}\text { Continuance } \\
\text { commitment }\end{array}$ & $\begin{array}{c}\text { Normative } \\
\text { commitment }\end{array}$ & $\begin{array}{c}\text { Procedural } \\
\text { justice }\end{array}$ & Affect & Loyalty & Contribution & $\begin{array}{c}\text { Professional } \\
\text { respect }\end{array}$ \\
\hline$\alpha$ & 0.94 & 0.95 & 0.95 & 0.97 & 0.92 & 0.85 & 0.87 & 0.84 \\
\hline$(\mathrm{Cr})$ & 0.95 & 0.96 & 0.96 & 0.97 & 0.95 & 0.91 & 0.92 & 0.90 \\
\hline AVE & 0.70 & 0.73 & 0.73 & 0.69 & 0.87 & 0.77 & 0.79 & 0.76 \\
\hline $\begin{array}{l}\text { Square root of } \\
\text { AVE }\end{array}$ & 0.84 & 0.85 & 0.85 & 0.83 & 0.93 & 0.88 & 0.89 & 0.87 \\
\hline
\end{tabular}

According to Fornell and Larcker (1981), the square root of AVE for a variable should be greater than the correlation of that variable with the other research variables. In this stage, the values for square root of AVE were calculated and then, according to Table (4), the obtained values were replaced on the diagonal of the matrix of "latent variable correlation".

Table 4: Variables correlation

\begin{tabular}{|l|c|c|c|c|c|c|c|c|}
\hline Variables & $\begin{array}{c}\text { Professional } \\
\text { respect }\end{array}$ & $\begin{array}{c}\text { Affective } \\
\text { commitment }\end{array}$ & $\begin{array}{c}\text { Continuance } \\
\text { commitment }\end{array}$ & $\begin{array}{c}\text { Normative } \\
\text { commitment }\end{array}$ & $\begin{array}{c}\text { Procedural } \\
\text { justice }\end{array}$ & Affect & Loyalty & Contribution \\
\hline Professional respect & 0.872 & & & & & & & \\
\hline Affective commitment & 0.680 & 0.838 & & & & & & \\
\hline Continuance commitment & 0.703 & 0.984 & 0.855 & & & & & \\
\hline Normative commitment & 0.682 & 0.995 & 0.980 & 0.855 & & & & \\
\hline Procedural justice & 0.621 & 0.792 & 0.794 & 0.793 & 0.833 & & & \\
\hline Affect & 0.977 & 0.690 & 0.710 & 0.694 & 0.629 & 0.933 & & \\
\hline Loyalty & 0.957 & 0.645 & 0.665 & 0.650 & 0.622 & 0.953 & 0.877 & \\
\hline Contribution & 0.967 & 0.684 & 0.698 & 0.688 & 0.638 & 0.977 & 0.968 & 0.892 \\
\hline
\end{tabular}

\subsection{Population, sample and sampling method}

The staff of Social Security Organization of Rasht make up the study population. In Rasht, Iran, this organization consists of headquarters and three branches. In the present study, stratified sampling method was used and a specified number of samples were selected corresponding to each area. The number of samples was assigned to each unit based on the portion of each divided branch from the total sample. The descriptive statistics were analyzed using SPSS (version 19) and the inferential statistics were analyzed by smart PLS (version 2). One of the main characteristics of Partial Least Squares (PLS) in testing hypotheses and path analysis is that it is not sensitive to the number of the samples. According to some researchers, the minimum sample required for PLS analysis is the highest value obtained from one of the known rules presented by Barkly et al. (1995):

1. Ten multiplied by the number of indices of measurement model for a structure that has the highest index (representative or item) among the measurement models of the main research model; in this study, the upmost index for the organizational commitment structure is 24 and therefore the sample which is ten times bigger is estimated to be 240 .

2. Ten multiplied by the most available relations in the structural part of the main research model (the maximum number of variables that predict a variable directly) which is associated with a variable. According to the presented model, the highest correlation (the number of direct preceding variables) belongs to organizational commitment and is equal to 2 . Accordingly, the sample size is estimated to be 20 .

3. Some researchers have suggested that in populations with unclear size, in addition to the value obtained by the two above-mentioned rules, the amount obtained from the following formula with an accuracy of 0.1 should also be taken into account and the highest obtained value should be selected (Jamshidi \& Khani, 2013). 
Equation (1)

$$
n=\left[\frac{{ }^{\frac{\alpha}{2}} \mathrm{X}_{\delta}}{\varepsilon}\right]^{2}
$$

Where $Z \mathrm{a} / 2$ is the amount of standard normal probability at a level. Since the error rate in the present study was 0.05 , the amount of $\mathrm{Za} / 2$ at the $95 \%$ confidence level is 1.96. $(\varepsilon)$ is the desired accuracy for the researchers that are assumed to be 0.01 . $(\sigma)$ is also the standard deviation of the population, which can be estimated by the following formula:

Equation (2)

$$
\sigma=\frac{\max \left(x_{i}\right)-\min \left(x_{i}\right)}{6}
$$

Since a five-point Likert scale questionnaire was used for this study, the largest value was 5 and the smallest one was 1. Therefore, the standard deviation would be 0.67 . This is the maximum standard deviation.

$\sigma=\frac{5-1}{6}=0.67$

Thus, based on the proposed formula, the sample size is:

$n=\left[\frac{1.96}{0.01} X_{0.67}\right]^{2}=171$

Comparing the numbers 20,240 and 171 , which were obtained from the three rules above, the maximum amount, i.e. 240 , was selected as the minimum required sample.

Table 5: Allocation of samples to the selected units based on stratified random sample

\begin{tabular}{|l|c|c|c|c|}
\hline & Population size & Sample size & Distributed questionnaire & Acceptable returned questionnaire \\
\hline Headquarters & 97 & 75 & 84 & 78 \\
\hline Branch 1 & 87 & 67 & 76 & 73 \\
\hline Branch 2 & 71 & 55 & 62 & 60 \\
\hline Branch 3 & 55 & 43 & 48 & 37 \\
\hline Total & 310 & 240 & 270 & 248 \\
\hline
\end{tabular}

In order for the researchers to access to more samples and in order to avoid the risk of reduction of the number of samples due to possibility of receiving inapplicable questionnaires, 270 questionnaires were considered to be sufficient for this study. Thus, 270 questionnaires were distributed among 4 units, 248 of which were returned and used for data analysis; thus, the questionnaire return rate was 91.9 percent.

\subsection{Data analysis}

\subsubsection{Profile of respondents}

A total of 248 subjects participated the study, among whom 138 were male (56\%) and 110 were females (44 \%). Most of the respondents (47.2\%) held BA and the lowest proportion of them were undergraduates (11.7\%). Most of the respondents (29.4\%) had 2 to 5 years of job experience, $28.6 \%$ of them had 10 to 20 years of job experience, $25.4 \%$ had 5 to 10 years of job experience, $11.7 \%$ had 20 years of job experience and $4.8 \%$ had less than 2 years of job experience. Most of the respondents (49.2\%) were between the ages of 30 to 40 and the lowest proportion (2.4\%) was over 50 years of age. In terms of marital status, $86.7 \%$ of the respondents were married and $13.3 \%$ were single.

\subsubsection{Testing research hypotheses}

Figure (2) shows the structural equation modeling of the study which is used to answer the research question and test research hypotheses through Smart PLS. In this figure, the following cases can be seen: factor loadings of representatives, coefficient of determination $\left(R^{2}\right)$, standard coefficients paths model (standard beta) and the values of $t$ statistic that indicates whether the relationship between the variables is significant or not. According to this model, it can be said that about $70 \%$ of organizational commitment can be predicted by the two variables LMX and procedural justice; 
in addition, $40 \%$ of procedural justice can be predicted by of the LMX variables. According to the coefficient path, about $64 \%$ of LMX is related to procedural justice; procedural justice is then about $60 \%$ associated with organizational commitment. Since LMX is approximately $32 \%$ associated with organizational commitment, i.e. for every unit increase in LMX, the organizational commitment increases by $32 \%$; then the procedural justice can strengthen the relationship between LMX and organizational commitment and can lead to better organizational commitment.

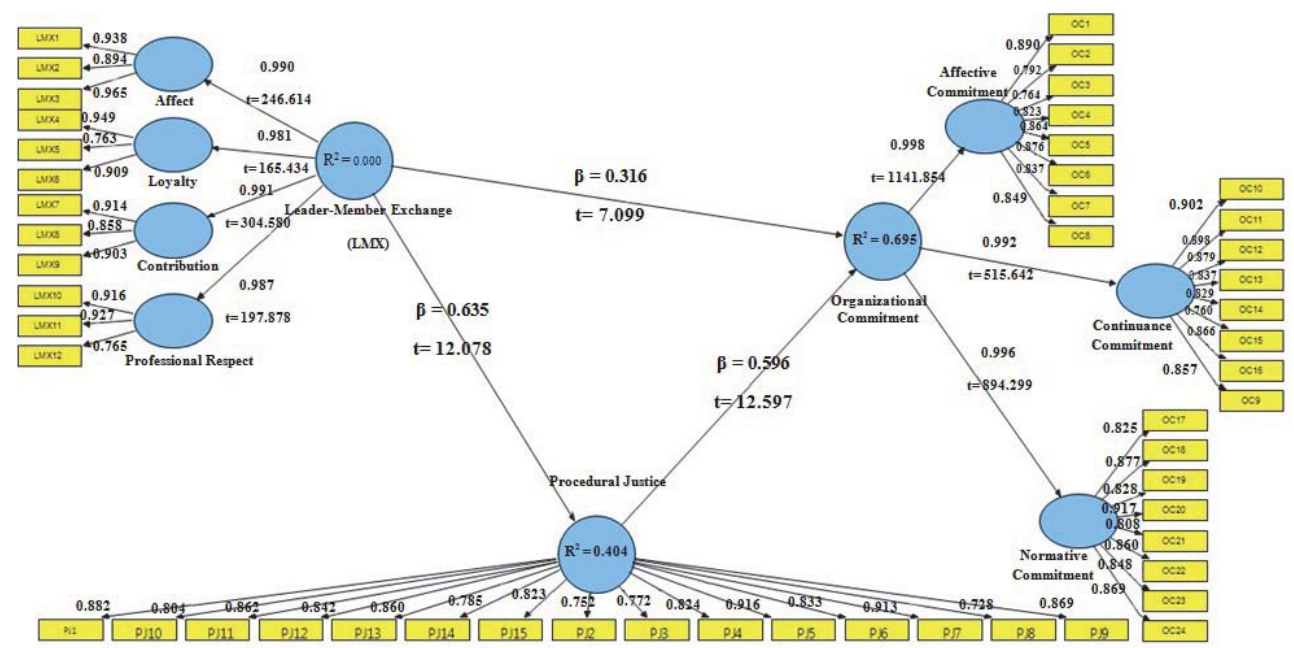

Figure.2: Structural equation modeling of the study based on research questions and hypotheses

Table 6: Summary of the software outputs for testing hypotheses

\begin{tabular}{|l|c|c|c|c|}
\hline Hypothesis & $\begin{array}{c}\text { Standardized path } \\
\text { coefficient }(\beta)\end{array}$ & (T Statistics) & Sig. & $\begin{array}{c}\text { Acceptance or rejection } \\
\text { of hypothesis }\end{array}$ \\
\hline LMX -> Procedural justice & 0.636 & 12.078 & Sig<0.05 & Accepted \\
\hline LMX -> Organizational commitment & 0.316 & 7.099 & Sig $<0.05$ & Accepted \\
\hline Procedural justice -> Organizational commitment & 0.596 & 12.597 & Sig<0.05 & Accepted \\
\hline
\end{tabular}

The research hypotheses were tested and the results are shown in Figure (2) and Table (6):

\subsubsection{Testing the first sub-hypothesis}

The standardized path coefficient was 0.636 , which indicates a positive relationship between LMX and procedural justice. This means that for the increase in every unit of LMX, procedural justice increases by 64 percent. Given that the amount of $t$ statistic is about 12.078, and this value is greater than the boundary value of 1.96 , it could be accepted by at least $95 \%$ confidence that LMX is significantly correlated with procedural justice and therefore the hypothesis pointing to the relationship between LMX and procedural justice is confirmed.

\subsubsection{Testing the second sub-hypothesis}

The standardized path coefficient is 0.316 , which indicates a positive relationship between LMX and organizational commitment. This means that by increasing one unit in the LMX, the organizational commitment increases by 32 percent. As can be seen in the tables, the t-statistic is 7.099 , which is greater than the boundary value (1.96). As a result, it can be accepted by at least $95 \%$ confidence that LMX is significantly correlated with organizational commitment and consequently the hypothesis indicating the relationship between LMX and organizational commitment is accepted. 


\subsubsection{Testing the third sub-hypothesis}

The standardized path coefficient was 0.596 , which indicates a positive relationship between procedural justice and organizational commitment. This means that by increasing one unit on procedural justice, organizational commitment increases by 60 percent. As shown, the t-statistic is about 12.597, which is greater than the amount of boundary value (1.96). As a result, it can be accepted by at least $95 \%$ confidence that procedural justice is significantly correlated with organizational commitment and consequently the hypothesis pointing to the relationship between procedural justice and organizational commitment is confirmed.

\subsubsection{Testing the main hypothesis}

Since LMX is significantly correlated with procedural justice and procedural justice is also significantly associated with organizational commitment, the assumption indicating the mediating role of procedural justice is confirmed. In order to examine whether this variables is a complete or partial mediator, the hypothesis of direct relationship between LMX and organizational commitment must be taken into account. Because of the direct, significant relationship between LMX and organizational commitment, it can be concluded that procedural justice plays a partial role as a mediator. This is because, in addition to indirect relationship, the LMX variable is, to some extent, directly correlated with organizational commitment.

\section{Conclusion}

The overall results obtained from the coefficient of determination belonging to organizational commitment and procedural justice indicates that almost $70 \%$ of the organizational commitment can be predicted by the two variables LMX and procedural justice and about $40 \%$ of procedural justice can be predicted by LMX. Examining the model by Smart PLS software suggests that the hypothesis is accepted; this indicates that procedural justice, LMX and all its aspects (interest, loyalty, contribution and professional respect) are correlated with organizational commitment and each of its three dimensions (affective, constant, and normative commitment). It also shows a significant positive relationship between LMX and its dimensions with procedural justice. According to the findings of this investigation, it was observed that the contribution aspect has the highest relationship and loyalty has the least relationship with procedural justice and organizational commitment. Thus, strengthening the contribution of the staff to their leaders plays a significant role in building organizational commitment. According to Golmohammadi (2013), contribution is the current level of professional activities of the staff and members in order to achieve mutual objectives. Therefore, administrators are recommended to create positive interaction and a sense of cooperation and contribution in order to assist and support their employees. They are also recommended to develop mutual respect and friendly atmosphere in the organization, listen to their staff's feedback and respect their opinions. They should also bring justifiable explanations if rejecting their staff's opinions and criticism. After contribution, the interest aspect accounted for the largest portion in the mentioned relationship; this has more to do with personal appeal to professional values. Thus, this aspect of LMX can be strengthened by tolerance, good mood, positive attitude and modest behavior. The professional respect, that is the reputation of each member within or outside the organization, was ranked third. This can be maximized by appointing the staff based on their merit and inservice training. The loyalty found to be the least effective dimension; this aspect is related to supporting the goals and personal characteristics of members. It can be improved by identifying the differences, strengths and weaknesses, as well as giving freedom and a sense of sharing through mandating and appreciating the staff's capabilities. The first subhypothesis of the study was confirmed by Lee (2000) who showed significant relationship between LMX and procedural justice. He declared that LMX is the positive predictive of procedural and distributive justice. Wang et al. (2010) also found a significant relationship between LMX and procedural justice. Thus, results of the above-mentioned research are consistent with those of the present study. Ansari et al. (2007) found professional respect in LMX as the only aspect which correlates with and positively and strongly affects procedural justice atmosphere. However, the current study revealed that all aspects of LMX are correlated with procedural justice; in this regard, the most relevant aspect is contribution and the least relevant one is loyalty. Thus, by improving the quality level of exchanges between managers and employees in Social Security Organization, particularly by making a sense of cooperation between the staff, procedural justice will be perceived at a high level (up to $64 \%$ of the increase in LMX).

The second sub-research hypothesis of this study is confirmed by Ansari et al. (2007). However, it must be mentioned that the interest aspect in LMX is related to all components of organizational commitment, though this relationship is negative for constant commitment. On the other hand, the contribution aspect in LMX is correlated with all the components of organizational commitment, but affective commitment. Hung et al. (2004) showed that professional 
respect had a positive impact on affective commitment and that contribution changed into the predictors of normative commitment. Interest in LMX had a negative effect on constant commitment while contribution had a positive impact on it. However, in this study all aspects of LMX had significant positive relationship with all dimensions of organizational commitment. In their study, Leow and Khong (2009) found significant positive correlation between the loyalty in LMX and organizational commitment, affective and normative aspect of organizational commitment; they also showed a significant positive correlation between contribution in the LMX and constant commitment. Reviewing previous studies, Leow and Khong (2009) reported the confirmation of positive relationship between LMX and organizational commitment; they also stated that LMX significantly predicts organizational commitment. In their study which is based on LMX theory, they concluded that LMX is positively correlated with organizational commitment. Therefore, this positive correlation suggests that members should feel that their managers recognize their abilities and contribution. As a result, they better respect such managers; this, in turn, will lead to a further increase in organizational commitment. Thus, LMX can be a useful tool for the staff to progress in their career life and to improve their commitment to the organization.

In addition to the fact that the third sub-hypothesis of this study was confirmed by Yousaf (2008) as well as Bahramzadeh and Yadegari (2009), Bakhshi et al. (2009) also found a significant relationship between procedural justice and organizational commitment. Ansari et al. (2007) stated that procedural justice atmosphere is associated with all the elements of commitment. However, the impact of constant commitment is less than affective and normative commitment. The findings of the studies mentioned are in line with those of this study. Leow and Khong (2009) found that organizational justice has a significant relationship with organizational commitment. The results of their research showed that procedural justice in high levels leads to mutual positive relationship with emotional and normative commitment at all levels. Wang et al (2010) found that the correlation between procedural justice and affective commitment is significant and positive, while its relationship with normative commitment is negative. The results of testing the study hypotheses in Dehghanian et al.'s (2012) confirm the significant positive correlation between organizational justice and organizational commitment. Procedural justice also has a significant relationship with affective and normative commitment, while it doesn't have any significant relationship with constant commitment. This means that if procedural justice increases in an organization, it has no impact on constant commitment of the staff to the organization. They also found that the more commitment to observe the organizational procedural justice by managers, the more the organizational commitment will be found. The results of the present study showed that procedural justice has a positive and significant relationship with all components of organizational commitment and that constant commitment is one of the dimensions of organizational commitment that is under the influence of procedural justice. That means, in addition to the perception of justice, the staff of Social Security Organization of Rasht are sensitive to the increase in the wasted cost of the organization (the cost of leaving the organization or the rewards of being motivated to stay in the organization). Ahmed (2014) also examined the impact of organizational justice on affective commitment and found a strong positive relationship between procedural justice and emotional commitment; this is consistent with the findings of this study. The results of testing the third hypothesis in this study are not aligned with those of Lee (2000), who unexpectedly showed a negative relationship between the perception of procedural justice and organizational commitment. Therefore, it is suggested that efforts should be made to increase procedural justice by doing the following practices: identifying obstacles, defining objectives, taking a justice-based strategy, making fair decisions, taking fair procedures, utilizing and accessing rules for all, creating equal opportunity for all the staff to provide feedbacks and suggestions (negotiations), tolerating the opposite opinions, being transparent, providing good working conditions and environment (space, facilities and safety), fairly distributing resources, evaluating performance, taking fair and unbiased approach to deal with the individuals' expertise, not comparing the job with the other jobs and finally, not prioritizing different jobs. If the staff of the organization are fully aware of the payment policies, they don't find differences in the remuneration unfair; since they are sure the policy for compensating the services is an open policy which is accurately and unbiasedly applied. Thus, if Social Security Organization can give its employees a proper understanding and perception of procedural justice, it can increase or stabilize the staff's commitment. The overall results obtained from this study suggest that all the hypotheses are accepted; this indicates the effect of LMX on procedural justice. In fact, the procedural justice is as a mediator that has a significant relationship with LMX. Since procedural justice is also significantly associated with organizational commitment, the assumption indicating the mediating role of procedural justice is confirmed. In a study conducted by Ansari et al. (2007), it was shown that procedural justice atmosphere is a mediator in the effect of LMX on three components of organizational commitment. Yousaf (2008) found that all aspects of organizational justice play a mediating role in the relationship between LMX and organizational commitment. Lee (2000) stated that LMX impacts organizational commitment through its effects on organizational justice. He predicted that distributive and procedural justice work as a mediator in the relationship between LMX and organizational commitment. Thus, the result of these researches is consistent with that of the present study. Since LMX creates a positive attitude among staff through procedural justice 
and as employees are looking for mutual interpersonal trust, organizations must learn how to build such trust and mutual support among the personnel, leaders and followers and how to increase the quality of the exchanges among the parties. Therefore, it is recommended that organizations increase the quality of the exchanges by stabilizing the behavior on the basis of merit and by creating a sense of collaboration, benevolent, kindness, loyalty, honesty, openness and transparency. Intimate relationship together with a lawful behavior between general manager and the staff to the extent that employees can have constructive feedback will make clear understanding of justice and thus organizational commitment. Therefore, managers of Social Security Organization can take into account LMX quality in order to create mutual trust between themselves and their employees. They can also fairly identify the potentials of their employees, improve procedural justice and strengthen their commitment to the organization.

\section{The Study Limitations and Suggestions for Future Research}

Generally, every research suffers from some limitations and problems and a researcher face with some problems in achieving the goals and objectives outlined in his or her study. Therefore, he or she must identify them and try to fix them. What follows is among the limitations and problems of this research:

In the present study, the role of demographic factors in the relationship between the variables was not studied. The extent to which demographic variables such as education, age and work experience can affect or modify the relationship between the variables studied in the present investigation is among the issues that deserve consideration by future researchers.

In the present study, in order to prevent the excessive number of items in the questionnaire, tiring the respondents and reducing the quality of responses, and given the fact that following fair approaches in decision-making process and implementing them is regarded as a value for the staff, procedural justice was selected as a mediating variable. It must be mentioned that, based on the previous studies, procedural justice is one of the important aspects of organizational justice. It is suggested that other dimensions of organizational justice such as distributive and communicational justice be examined in future studies.

\section{References}

Ahmed, H. T. (2014). Impact of organizational justice on affective commitment: mediating role of psychological ownership and organizational identification. IOSR Journal of Business and Management, 16(1), 58-63.

Allen, N. J., \& Meyer, J. P. (1990). The measurement and antecedents of affective, continuance and normative commitment to the organization. Journal of Occupational Psycholo, 63, 1-18.

Ansari, M. A., Hung, D. K. M., \& Aafaqi, R. (2007). Leader-member exchange and attitudinal outcomes: role of procedural justice climate. Leadership \& Organization Development Journal, 28(8), 690-709.

Bahramzadeh, H., \& Yadegari, M. (2009). Analysis of the relationship between organizational justice and organizational commitment of girl's secondary schools employees for Mashhad school districts. Journal of Tomorrow Management, 8(21), 55-65.

Bakhshi, Arti; Kumat, Kuldeep \& Ekta, Rani. (2009). Organizational justice perceptions as predictor of job satisfaction and organization commitment. International Journal of Business and Management, 4(9), 145-154.

Blader, S. L., \& Tyler, T. R. (2003). A four-component model of procedural justice: defining the meaning of a "fair" process. Personality and Social Psychology Bulletin, 29(6), 747-758.

Chooi Hwa, A. M., Jantani, M., \& Ansari, M. A. (2009). Supervisor vs. subordinate perception on leader-member exchange quality: a Malaysian perspective. International Journal of Business and Management, 4(7), 165-171.

Chung, J. Y., Jung, C. S., Kyle, G. T., \& Petrick, J. F. (2010). Servant leadership and procedural justice in the U.S. national park service: the antecedents of job satisfaction. Journal of Park and Recreation Administration, 28(3), 1-15.

Darvish, H. \& Farzanehdokht, N. (2010). Leader-member exchange (LMX) in creating energy and outbreak creation at work. Public Administration (Tehran University), 2(5), 37-54.

Dehghanian, H., Sabour, E., \& Hojjati, A. R. (2012).The relationship between the components of organizational justice and organizational commitment in an insurance company. Insurance Journal, 28(2), 153-180.

Fornell, C., \& Larcker, D. F. (1981). Evaluating structural Equation Models with Unobservable variables and Measurement Error. Journal of Marketing Research, 18(1), 39-50

Ghasemi, B., \& Keshavarzi, R. (2014). The relationship between organizational climate, organizational commitment and organizational citizenship behavior in a hospital environment. Reef Resources Assessment and Management Technical Paper, 40(2), 759-773.

Golmohammadi, E., Kafcheh, P., \& Soltanpanah, H. (2013). Leadership style and strategic thinking at the organizational level. Strategic Management Studies, (15), 93-114.

Hezarjaribi, J. (2011). Study of sense of social justice and the factors influencing it (case study in Tehran). Journal of Applied Sociology, 22(3), 41-62.

Hung, D. K. M., Ansari. M. A., \& Aafagi, R. (2004). Fairness of human resource management practices, leader-member exchange and 
organizational commitment. Asian Academy of Management Journal, 9(1), 99-120.

Jamshidi, M. H. M., \& Khani, N. (2013). PLS guide: a practical guide to design and analysis of structural equation models in social science research using PLS (Partial Least Squares), USA: Create Space.

Kiersch C. E. (2012). A multi-level examination of authentic leadership and organizational justice in uncertain times. Ph.D. Thesis, Colorado: Colorado State University.

Konovsky, M. A. (2000). Understanding procedural justice and its impact on business organizations. Journal of Management, 26(3), 489-511.

Lambert, E. (2003). The impact of organizational justice on correctional staff. Journal of Criminal Justice, 31(2), 155- 168.

Lee, H. R. (2000). An empirical study of organizational justice as a mediator of the relationships among leader-member exchange and job satisfaction, organizational commitment, and turnover intentions in the lodging industry. Ph.D. Thesis, Virginia: Virginia State University.

Leow, K. L., \& Khong, K. W. (2009A). Organizational commitment: the study of organizational justice and leader member exchange (LMX) among auditors in Malaysia. International Journal of Business and Information, 4(2), 161-198.

Leow, K. L., \& Khong, K. W. (2009B). The study of mentoring and leader- member exchange (LMX) on organizational commitment among auditors in Malaysia. Sunway Academic Journal, 6, 147-172.

Liden, R. C., \& Maslyn, J. M. (1998). Multidimensionality of leader-member exchange: an empirical assessment through scale development. Journal of Management, 24(1), 43-72.

McMahon, B. (2007). Organizational commitment, relationship commitment and their association with attachment style and locus of control. MS Thesis, Georgia: Georgia Institute of Technology.

Nasurdin, A. M., \& Ahmad, Z. A. (2001). The effect of procedural justice on organizational commitment in the Malaysian context: do men and women differ? Asian Academy of Management Journal, 6(1), 31-47.

Pourezzat, A. A., Ehsani, M, N., Yazdani, H. R., \& Fayez, K. (2013). A comparative analysis of the various dimensions justice in the climate of the organization and organizational loyalty: research on the IT organization. Public Administration, 5(1), 65-88.

Rasouli, R., \& Shahaie, B. (2009). The impact of leader-member exchange approach on the job satisfaction of branches of Tehran social security staff. Management Landscape, (33), 67-84.

Scandura, T. A. (1999). Rethinking leader-member exchange: an organizational justice perspective. Leadership Quarterly, 10(1), 25-40.

Scandura, T. A., \& Pellegrini, E. K. (1999). Trust and leader-member exchange a closer look at relational vulnerability. Journal of Leadership \& Organizational Studies, 15(2), 101-110.

Wang, P. Q. (2014). An investigation of how gender moderates the impact of leader-member exchange (LMX) on front-line employees' work outcomes in the hospitality industry. MS Thesis, Auckland: Auckland University of Technology.

Wang, X., Liao, J., Xia, D., \& Chang, T. (2010). The impact of organizational justice on work performance mediating effects of organizational commitment and leader-member exchange. International Journal of Manpower, 31(6), 660-677.

Yousaf, A. (2008). The role of organizational justice in the relationship between LMX, organizational commitment and intent to turnover. MS Thesis, Twente: University of Twente. 